patients. Future training sessions will widen the scope of available bedside companion support.

\section{P-232 BEFORE WE CHANGE, LET US UNDERSTAND: A PROSPECTIVE CHARACTERISATION OF HOSPICE INPATIENTS}

${ }^{1}$ Libby Milton, ${ }^{2}$ Erna Haraldsdottir, ${ }^{1}$ Anne Finucane, ${ }^{1}$ Martyn Bijak, ${ }^{2}$ Duncan Brown, ${ }^{1}$ Hilary Ford, ${ }^{2}$ Jacqui Stone, ${ }^{2}$ Dot Partington. ${ }^{1}$ Marie Curie, Edinburgh, UK; ${ }^{2}$ St Columba's Hospice, Edinburgh, UK

\subsection{6/bmjspcare-2019-HUKNC.254}

Background Hospice service redesign aims to achieve the greatest impact for the greatest number of people within limited resources. The strategic direction within the NHS is towards care as close to home as possible, reducing avoidable admissions and improving patient experience of end of life care. However, there is little published evidence describing patient use of a specialist palliative care inpatient service, despite this significant resource.

Aim To enhance the understanding of why patients are admitted to two hospice inpatient units within one Health Board area, to describe the characteristics of patients admitted and to explore their needs and wishes in this process.

Method We are conducting a prospective mixed methods evaluation. Using case note review, we are collecting data on approximately 250 hospice inpatient admissions over a four month period. In addition, we are conducting up to 40 interviews with patients and carers to explore expectations and feelings around the admission; and seek feedback from the referrer and the receiving staff about appropriateness of admission and alternatives to admission.

Results We will present preliminary data on the reasons for referral to the hospice inpatient services, describe characteristics of patients referred including Adapted Karnofsky Performance Score, Phase of Illness and iPOS at time of referral; along with preliminary qualitative findings regarding patient and carer perspectives about hospice inpatient admission.

Our findings will inform our understanding of the use of hospice inpatient services and how resources can be most effectively allocated to meet patient and family needs and preferences within a locality. This will allow meaningful service redesign, ensuring the patient experience informs change.

\section{\begin{tabular}{|l|l}
\hline P-233 DYING TO WORK TOGETHER - PARTNERSHIP AND \\
\hline
\end{tabular} POTENTIAL}

${ }^{1}$ Liz Arnold, ${ }^{2}$ Shane Moody. ${ }^{1}$ Mountbatten, Newport Isle of Wight, UK; ${ }^{2}$ Isle of Wight NHS Trust, Newport, Isle of Wight, UK

\subsection{6/bmispcare-2019-HUKNC.255}

'The path to successful partnerships is littered with many attempts that have failed' (Mitchell \& Karoff, 2015).

Over a period of more than a decade, the hospice had an in-reach specialist palliative care team working in the local hospital, during which time the hospital developed its own end of life care team. Both teams worked in isolation, challenged by different structures, values and approaches. It became clear that expectations regarding leadership, goals, roles, processes and responsibilities of partnership working differed significantly. The concept of the two teams working collaboratively was strong, but many challenges soon emerged. Joining forces to make a difference was not going to be an easy prospect. We had not aligned our values and as a result, became disconnected in our day-to-day interactions to such an extent that it was on the threshold of being unsustainable.

In October 2018, the Trust appointed a Clinical Director for End of Life Care and this was the beginning of the integration of the two teams. Together with the Director of Nursing from the hospice, leadership of this team is based on trust in each other's ability to lead effectively and with integrity. One of the early pieces of work we commenced together was to acknowledge the two organisations values, missions and operating principles and collectively agree our operational values and behaviours moving forward.

For this partnership to be successful, it will require strong leadership, common understanding, a shared vision and purpose, mutual understanding and an acceptance of differences. It will require resilience in the face of inherent tensions and inevitable conflict. Partners frustrate each other; partners will let each other down - if we can accept these challenges and work with them, together we have a much better chance of making a difference.

\section{P-234 SPIRITUAL CARE SUPPORT WITHOUT WALLS AT ROWCROFT HOSPICE}

Jo Anthony, Katie Sturch, Bev Stevenson, Daniela Hopkins, Nicola Monks, David Holmes, Dawn Stirk, Julie Lofthouse, Gill Horne. Rowcroft Hospice, Torquay, UK

\subsection{6/bmjspcare-2019-HUKNC.256}

Background Spirituality is a hugely important part of the end of a person's life: what matters to them most, who they are; their story; their friends/family; those that care for them. When the hospice's existing Anglican Chaplain retired after 17 years, an opportunity arose for us to review our provision of spiritual care, moving away from a traditional chaplaincy model to support our ever-changing communities. Evidence, identified as part of the process, highlighted the gaps in the care we already provide.

Aim To create an updated model for spiritual care, led by a newly appointed Spiritual Care Specialist, achieving inclusive support for all that come in to contact with Rowcroft regardless of religion, beliefs, faith, or no-faith.

Method September 2018 - Jan 2019: we conducted a service evaluation, set up a Task and Finish Group which consisted of core representation across the organisation; different nurses from the ward attended each group, undertook a literature review, contacted other hospices, hospitals and Healthwatch Torbay, developed a Spiritual Care Model and gained Senior Management Board and Trustees buy-in.

Results A Spiritual Care Specialist was appointed. The existing on-site Chapel was de-registered and renamed The Sanctuary. Marriages, celebrations and other events for all (regardless of faiths, beliefs, religions) can take place in the space, also providing a 'quiet' space. There are seven further recommendations within the new model that will now be progressed to fully achieve the desired outcomes with the help of a Spiritual Care 'Custodian' Group. 